\title{
Six forms of variety in students' moral reasoning: an age-old distinction enabling new methods and findings
}

\section{Ylva Backman \& Viktor Gardelli}

To cite this article: Ylva Backman \& Viktor Gardelli (2015) Six forms of variety in students' moral reasoning: an age-old distinction enabling new methods and findings, Ethics and Education, 10:2, 227-240, DOI: 10.1080/17449642.2015.1051856

To link to this article: http://dx.doi.org/10.1080/17449642.2015.1051856

曲 Published online: 20 Jul 2015.

Submit your article to this journal $\pi$

Џll Article views: 148

Q View related articles $\longleftarrow$

View Crossmark data $\nearrow$ 


\title{
Six forms of variety in students' moral reasoning: an age-old distinction enabling new methods and findings
}

\author{
Ylva Backman* and Viktor Gardelli ${ }^{1}$ \\ Department of Arts, Communication and Education, Luleå University of Technology, 97187 Luleå, \\ Sweden
}

In this study, the age-old distinction between decision method and criterion of rightness, commonly employed in normative ethics, was used to attain a detailed understanding of inter- and intrapersonal variety in students' moral reasoning. A total of 24 Swedish students, 12-15 years of age, were interviewed. Inter- and intrapersonal varieties in and between the two dimensions of moral reasoning were found, constituting six novel forms of varieties. We describe several explanations proposed within the field of social-cognitive domain theory, and argue that these do not suffice to explain all the found forms of varieties in students' moral reasoning. Some limitations of the present study are discussed, and some suggestions for future research are given.

Keywords: education; ethics; moral reasoning; social-cognitive domain theory; well-being

\section{Introduction}

Moral reasoning is a basic component of moral education, character education and education for democracy (Zarinpoush, Cooper, and Moylan 2000), and it is one element of moral judgment (Bosco et al. 2010). Studying moral judgment levels is important for understanding teaching and instruction in ethics (Bosco et al. 2010). Higher quality of moral reasoning has been found to correlate with a lower tendency to delinquent behavior in adolescents and to less offending and criminal behavior (Beerthuizen, Brugman, and Basinger 2013; Palmer 2003; Raaijmakers, Engels, and Van Hoof 2005). Educating to help students develop their moral reasoning is important in order to "promote mutually rewarding relationships' (Senland and Higgins-d'alessandro 2013, 209), and it has been argued that it also has the potential to promote democratic abilities and reduce the influence of violent political extremism on students (Nilsson et al. 2015). Hence, knowledge of moral reasoning is one important component for building educational programs that can help reduce future unwanted behavior. It is a common view that an ethics education program ought to cultivate moral reasoning in learners (Bouchard and Morris 2012). Developing ethics education through focus on the development of moral reasoning is used in as varied contexts as business education, nursing education, professional education, special needs education, college education, and preschool education (Bebeau 2002; Chaparro et al. 2013; Mayhew and King 2008; McLeod-Sordjan 2014; Schmidt, McAdams, and Foster 2009;

\footnotetext{
*Corresponding author. Email: ylva.backman@1tu.se
} 
Senland and Higgins-d'alessandro 2013). Studying students moral reasoning is also used as a method for understanding a plethora of different educational matters, for assessing educational programs, curricula, and the effects of different educational changes and interventions (e.g., Bosco et al. 2010; Hurtado, Mayhew, and Engberg 2012; Mayhew and King 2008). Hence, a good framework for understanding students' moral reasoning is important from a methodological point of view for a broad variety of future educational research.

Interpersonal variety in students' moral reasoning and opinions has been of great concern to contemporary researchers in various fields (Backman et al. 2012; Rique and Camino 1997; Smetana 2006). Much attention has been paid to varying intrapersonal moral positions over time, with one of the most influential contributions being Kohlberg's theory of stage development (e.g., Kohlberg 1981, 1984). Besides critique concerning a diminished care perspective ${ }^{2}$ (Gilligan 1982; Gilligan and Wiggins 1988), Kohlberg's theory has been challenged through findings relating to intrapersonal contextual variety of moral judgment (Carpendale and Krebs 1992). According to Öhman and Östman (2007), it is a common experience today that our moral judgments vary in time and place. The alleged existence of such variations has bearing on which one of such disparate approaches to ethics in education as moral fostering or philosophical ethics (Gardelli, Alerby, and Persson 2014), ought to be taken.

A typical idea in the extensive field of social-cognitive domain theory (SCDT) (Nucci and Turiel 1978; Turiel 1983) is that varieties in moral judgments can be explained by variations in context. In other words, differences in context are considered as accounting for both inter- and intrapersonal differences in judgments. Both internal circumstances, such as a person's different informational assumptions (Wainryb 1991), and external circumstances, such as the person's involvement in an actual situation due to playing certain social roles and being in certain social relationships (Passini 2014; Smetana 2006), different characteristics of, and within, cultures (Wainryb 2006), ethnicity, gender, or socio-economic background (Smetana 2006), and whether the dilemma or situation that the research subject faces is one of personal, social conventional, or moral character (Nucci and Turiel 1978; Turiel 1983), have been proposed as explanatory factors.

The distinction between the personal, social conventional, and moral domain is commonly advocated in SCDT (Nucci and Turiel 1978, Smetana 1999), and bears resemblance to the long-lived distinction within normative ethics between conventional normative judgments and moral judgments (e.g., Kant 1988), which has been both extensively criticized (Foot 1972) and defended in recent times (Southwood 2011). Nonetheless, the three-part domain distinction has been crucial for the development of the research area, although its relevance has also been contested (Keefer 2006). Although not being less established in the field of normative ethics - being understood by philosophers of past times such as Sidgwick (1907) - the distinction between criterion of rightness and decision methods has rarely been used in empirical research, a distinction described further in 'Definitions and data processing.' If utilized, dimensions of moral reasoning not previously distinguished between in SCDT could be revealed, which could have different causal connections to variations in context.

In this study, we have employed the distinction between decision methods and criteria of rightness as an analytical tool in order to obtain detailed data about students' moral reasoning and provide a nuanced understanding of inter- and intrapersonal variety within the students' moral reasoning. The study aimed at answering the following two questions: 
(1) What forms of inter- or intrapersonal variety in the students' moral reasoning become evident by employing the distinction between decision method and criterion of rightness in the data processing?

(2) If there are such varieties, how do the SCDT explanations based on variations in context account for them?

Finally, we wish to note that the term 'moral' should, in this article, be interpreted in accordance with common definitions in normative ethics, including concepts, prescriptions, and principles of right and wrong, good and evil, and what one ought to, should, or should not do (see e.g., Blackburn 2008). Such a concept is broader than what is typically employed in SCDT (Nucci and Turiel 1978).

\section{Method \\ Participants, design, and procedure}

Twenty-four students, aged 12-15 years, from two municipally run schools, which were part of the compulsory school program, and located in the northern part of Sweden participated in the study. ${ }^{3}$ A qualitative design with open-ended interviews was used to collect data. The authors conducted the interviews using interview protocols with general questions such as 'How do you think people should behave towards each other in school?,' as well as hypothetical moral dilemmas with social content, concerning behavior such as lying, interfering in bullying situations, and violation of a friend's integrity on the Internet. The description of the dilemmas was followed by supplementary questions concerning what the student thought that a hypothetical student ought to do, and the reasons for that stated position, as well as the meaning of different expressions the student used. The frequency and nature of the supplementary questions were adjusted to aspects of the interview situation, such as how much the students talked, as well as the perceived selfconfidence of the interviewed student.

This research study was approved by the Regional Ethical Review Board (Dnr 45-2009 and 760-2010) in Sweden, and conducted in accordance with Swedish law concerning the code of ethical conduct (Ministry of Education and Cultural Affairs 2003). Informed consent was obtained from both students and parents, and no student withdrew from participation.

\section{Definitions and data processing}

After the interviews, the authors reviewed the students' responses by listening to the interviews, carrying out transcriptions, and reading the transcripts in several turns. The material was analyzed with use of the distinction between decision methods and criteria of rightness. The criteria of rightness are principles determining whether a given action is morally correct or not, while the decision methods are general ways of behaving in practical matters (Tännsjö 1998). For instance, some utilitarians advocate the rightness criterion called 'The Principle of Utility,' which Bentham described as:

... that principle which approves or disapproves of every action whatsoever, according to the tendency which it appears to have to augment or diminish the happiness of the party whose interest is in question: or, what is the same thing in other words, to promote or to oppose that happiness. (Bentham 2000, 14) 
Tännsjö (1998) claims that one should utilize a decision method that corresponds well to one's criterion of rightness. Accordingly, one alleged decision method for utilitarianism is to attempt to maximize expected happiness (Tännsjö 1998).

Another influential principle of moral rightness, often attributed to Kant, is the categorical imperative: "Act only according to that maxim by which you can at the same time will that it should become a universal law' (Kant 1988, 268). According to Kant, immorality involves a violation of the categorical imperative, and is thereby irrational. Johnson (2004) has considered this formulation of the categorical imperative to recapitulate a certain procedure for moral reasoning. He describes the first three steps of the procedure, according to his interpretation, as follows:

First, formulate a maxim that enshrines your reason for acting as you propose. Second, recast that maxim as a universal law of nature governing all rational agents, and so as holding that all must, by natural law, act as you yourself propose to act in these circumstances. Third, consider whether your maxim is even conceivable in a world governed by this law of nature. (Johnson 2004, 10)

If a maxim fails to pass the third step, the negation of the maxim is a perfect duty (one that must always be followed).

In this study, the term 'decision method' is not taken to be restricted to decisions regarding risk, including calculations of consequences, as commonly acknowledged in decision theory (Resnik 1987). Rather, it can as well include the imperatives to be just, brave, or pragmatic, provided that they are considered applicable to practical matters and hold some (while not necessarily exhaustive) generality. Moreover, the term 'criteria of rightness' can refer to principles determining whether a given decision method is morally correct or not, and not only to principles determining the moral status of a certain action.

Decision method and rightness criterion are often conceived of (e.g., Bales 1971; Sidgwick 1907; Tännsjö 1998) as two relevant parts of a moral framework. ${ }^{4}$ In the following, we will denote these as different moral reasoning 'dimensions.'

The data processing proceeded in accordance with the following steps (1-6):

(1) The transcriptions were read several times, and sections of interest were marked down for further review.

(2) The highlighted material was interpreted in order to categorize the different parts as being either reasoning in the decision method dimension or the criterion of rightness dimension. Parts of the texts were interpreted in relation to the interpretation of the whole, and vice versa.

(3) Each extract was interpreted on the basis of our understanding of classical and contemporary ethical theories. The aim was to understand the nature and type of reasoning that the student was expressing, and to facilitate comparison. The parts were classified according to its moral value type, i.e., what kind of normative theory or moral position coheres with that section of reasoning. For example, if two students would have expressed reasoning based upon two different perceived virtues, both utterances would have been characterized as expressing virtue ethics.

(4) The interpretations were revisited and searched for errors or discrepancies in our interpretations.

(5) Each extract was then classified according to (i) which student expressed it, (ii) its dimension of moral reasoning, and (iii) its moral value type. 
(6) The data were synthesized by comparing the extracts, searching for interpersonal variety in decision method dimension, in criterion of rightness dimension, and in between the dimensions, as well as for intrapersonal varieties of the same forms. (For instance, a case of interpersonal variety in decision method dimension consists of two extracts from two different students, both being in the decision method dimension, and expressing different moral values or ethical theories.)

\section{Results}

Through utilizing the two dimensions of moral reasoning in the data processing, we found six forms of variety in the students' moral reasoning, denoted as follows: (i) interpersonal variety in decision method dimension, (ii) intrapersonal variety in decision method dimension, (iii) interpersonal variety in criterion of rightness dimension, (iv) intrapersonal variety in criterion of rightness dimension, (v) interpersonal variety between the two dimensions, and (vi) intrapersonal variety between the two dimensions.

In the presentations of (i)-(iv) below, we first provide a short description of interpersonal variety and, second, give a more exhaustive description of an example of intrapersonal variety. Interpersonal variety between the two dimensions of moral reasoning (v) can be inferred from the findings presented in (i)-(iv), as described below. In the presentation of (vi), an in-depth description of an example of intrapersonal variety is presented. The quotations used in the presentations of the findings have been translated into English by a professional translator.

\section{Variety in decision method dimension}

\section{(i) Interpersonal variety}

The students had several different ideas about how to behave toward each other. For instance, they emphasized virtues, such as being fair, kind, and honest, as ways to act toward others. Some underlined the importance of spending one's time and using one's powers to help other students in need, even when one ran the risk of being bullied or exposing oneself. On the one hand, some students argued that we should keep our promises, as well as never lie, and never promise to lie. On the other hand, some students explicitly claimed that it is acceptable to break promises as, for example, when someone else's well-being depends on it, or when it is perceived as necessary to break a promise in order not to violate someone's rights. Another position that was emphasized was that one has the moral right to control what information about oneself is posted online.

The 'golden rule' - do unto others as you would have them do unto you - was also advocated, as was not to bully or say mean things, and not to act violently toward peers in school. Another aspect highlighted by the students was the importance of standing up for oneself and one's values and beliefs.

As noted above, some students' reasoning concerned others' well-being. Some students said that one should perform those actions that had certain desirable consequences. For example, one student first argued that you ought to break a promise to a friend if a second friend has 'the right to know' the information that you promised not to tell. But the student then added that you should not break the promise given that the second friend does not know that you have this information, and that he or she therefore does not suffer from it. 
Caring perspectives and acting to promote certain close relations were also expressed. For example, some students said that whether or not you should break a promise depends on whether the one you made the promise to was a good friend or not.

In sum, the students expressed extensive interpersonal variety of ways of behaving toward each other. For example, the students, in their reasoning about decision methods, expressed values that could easily be understood from the perspective of several normative theories.

\section{(ii) Intrapersonal variety}

Instances of intrapersonal variety were also found. This will be illustrated by the example below with extracts from an interview with one of the students. This student was faced with a dilemma in which one hypothetical student had promised a classmate to tell the teacher that the classmate in question was ill and was therefore home from school, while in fact the classmate was not ill, but instead playing hooky.

Interviewer: What do you think [he] should do?

Student: Well, actually, he should say that this isn't how it is. So, well, the friend wouldn't take it too hard if he told about it. [...] If there were some reason, like if he [the friend] was going to do something, not play computer games or so, but if he [the friend] had some reason to do it, you can't say it. But if it's just because he wanted to do it ...

Interviewer: Yes, what could such a reason be ...?

Student: Like... I don't know. If he's like going somewhere in the afternoon. You know, if he like needs to relax about something, or if he feels generally lousy.

Interviewer: Mmm, OK. But if he doesn't. In other words, if it's just, for example like you said, that he wanted to play computer games?

Student: Mmm, yeah, but then you would tell it to the teacher right away.

Interviewer: What if [he] supposedly promised his classmate to say that he had stomach problems ....?

Student: Like, I would never promise someone that I would say that he had stomach problems if he was healthy.

Interviewer: But if you had promised. You would have agreed to do it, even if you now are saying that you wouldn't, but if we say you had done it ...

Student: Yes.

Interviewer: And what if it was so that [the classmate] actually felt bad about his parents' divorce, for example ...?

Student: (Interrupting) Then I would have said to the teacher that he had stomach problems.

Initially, the student reasoned in a highly pragmatic way, saying that the hypothetical student should act differently depending on what reasons the classmate had for remaining at home. However, when the interviewer emphasized the promise-making part of the dilemma, the student obliged by stating that he would never promise to tell this kind of a lie. It would probably be too rigid an interpretation to conclude that it is certain that the student considered there to be no exceptions from this rule merely because the student used the word 'never,' but it is warranted to conclude that the student expressed a much less pragmatic - here described as 'non-pragmatic' - way of behaving than in the 
previous replies. Then, given that the promise had already been made, the student returned to the pragmatic reasoning, stating that he would tell a lie if the conditions were of a certain kind. Hence, comparing the parts and whole of the student's reasoning, we can see that the student explicitly adhered to both pragmatic and non-pragmatic decision methods regarding the same hypothetical dilemma, but in different actions or different preconditions within it.

\section{Variety in rightness criterion dimension}

\section{(iii) Interpersonal variety}

The students emphasized duties as well as actual and hypothetical consequences as motives for behaving toward each other in school in the ways previously described. Accordingly, different rightness criteria were interpreted as being grounds for different decision methods. They also reasoned from diverse ethical perspectives in regard to both the same and different situations. Hedonistic qualities, such as pleasure or happiness, were characterized as morally significant. Some students also pointed to the relevance of maintaining a pleasant and nice atmosphere in school as well as being true to oneself. Some justified their views of the moral status of some behavior by referring to roles and to powers that one possesses when playing a certain role in a situation. Motives in terms of both egoistic and less narrow consequentialist reasoning were put forward, and duties such as compulsory school attendance were referred to as reasons for actions.

On the whole, the students expressed extensive interpersonal variety. Again, the students emphasized central characteristics or important parts from several of the wellknown theories from normative ethics, however, here with regard to criteria of rightness.

\section{(iv) Intrapersonal variety}

Some intrapersonal variety of reasoning regarding rightness criteria was manifested in the combination of referring, on the one hand, to consequences of actions and, on the other, to duties such as compulsory school attendance, regarding the same hypothetical situation. Another example of specific intrapersonal variety is the following, in which one of the students argued that you should be fair ${ }^{5}$ in school:

Interviewer: But why is it important to be fair in school?

Student: Well, it's not enjoyable to go to school if you get bullied all the time, is it?

Interviewer: No.

Student: So if no one is fair in school, no one will come here, and then there wouldn't be much point in having a school.

Interviewer: Mmm. OK! So it's for ...

Student: (Interrupts) Well, it feels nicer if people are fair with each other. It kinda gets, if you, if you just say, 'No, but I hate you,' just like that; that person will be angry with you, and it gets like... It's not so much fun to have a group project with that person later on.

Interviewer: No...

Student: No. And we do a lot of group projects.

The student argued that the effects of certain behavior in school are relevant for the moral status of that behavior. More precisely, the importance of being 'fair' in school was 
emphasized, since someone would get bullied otherwise. Moreover, the student valued having a nice time in school, and that being bullied would likely contribute to the opposite. It is not certain whether the student argued from, for example, egoistic, utilitarian, or altruistic grounds when stating the reason that it would not be very nice for the student or for a classmate to get bullied in school, but it is indeed quite certain that some kind of consequentialist considerations motivated the student's previous position on fairness. In the first, third, and fourth reply quoted above, the student referred to actual consequences of bullying or acting unfair to each other.

However, in the student's second reply quoted above, the stated position is different. There, the student made use of an argument similar to Kant's categorical imperative. If interpreted in accordance with Johnson (2004), the student could be seen as having first formulated the maxim, which is 'not be fair in school,' second recast this maxim as a universal law governing the universe of all the students in school, and third having considered whether the maxim is conceivable in the actual world. Given that no one would go to school if no one were fair in school, and that it would not be conceivable to have a school without any students, the maxim would not make it through the third step. Hence, the negation of the maxim would become a perfect duty, according to this reasoning procedure. Indeed, it is not at all certain that the student went so far as to hold that it is under no circumstances whatsoever allowed to not be fair in school, or to explicitly spell out all the steps, but the student's argument certainly resembles this Kantian type of reasoning.

It could be objected that the student's reasoning in the second reply is rather based on standard consequentialist reasoning - on an evaluation of actual consequences. Indeed, it might be that the student considered it probable that just because one person is unfair, everyone would actually become unfair, which in the long run would result in there being no students and no point in having a school at all. However, since most people have been the target of unfairness some time and have seen that this has not resulted in the whole population becoming unfair, this interpretation is less promising.

The above comparison of the different parts of the student's reasoning leads to the more general interpretation that the student seems to have argued from actual consequences as well as hypothetical consequences after recasting a maxim as universal law. Both kinds of reasoning were utilized in regard to the same behavior or character trait. In sum, one reasonable interpretation of this is that the student adhered to different rightness criteria and applied them to the same decision method.

\section{Variety between decision method and rightness criterion dimensions}

\section{(v) Interpersonal variety}

The existence of interpersonal variety between the two dimensions of moral reasoning can be inferred from the findings presented above, and the content of it follows from what is described in (i) and (iii) above. (In fact, the existence of all forms of interpersonal variety can be inferred from the intrapersonal variety described above, while the richness of it cannot.) Since there is at least one student that has displayed intrapersonal variety in each of the dimensions, whatever reasoning the first of the other students would express, it would constitute an interpersonal variety with at least one of the forms of reasoning expressed by the first student. Since there are several students, interpersonal variety between the dimensions exists. 


\section{(vi) Intrapersonal variety}

In line with the findings of intrapersonal varieties in the students' reasoning in decision method dimension and rightness criterion dimension, there were some examples of intrapersonal divergences between decision method and criterion of rightness in the students' reasoning. For instance, one student expressed allegiance to a virtuous decision method, while the criterion of rightness for that decision method was a consequentialist one. A different and more extensive example is illustrated below. The student had just underlined the importance of being 'kind' toward each other in school and described that one feature of being 'kind' is not hitting your peers:

Interviewer: So what does it mean for you to be kind? In other words, is it something more than not hitting and things like that, or what?

Student: No, but mostly like helping each other, being a little generous, and things like that. Not being too egoistic, in other words only thinking of yourself.

Interviewer: Mmm. OK. Why shouldn't you be egoistic then, for example?

Student: Because, like it feels so strange to be with someone who is much too egoistic, like only thinking of himself. For example, if you play soccer, it's not much fun to play soccer with someone who is egoistic.

The student indicated that if one has the character trait of being 'kind' one is also not egoistic, which indicates that the student considered the concept of a non-egoistic character trait or non-egoistic actions to be included in the concept of being 'kind.' In justifying the behavior of not being egoistic, the student refers to the consequences of being egoistic. How the classmates feel if one is egoistic was relevant to the ascribed moral status of the behavior.

Later on during the interview, the same student considered the hypothetical dilemma regarding playing hooky, and then held it implausible for the hypothetical student to make the promise to the classmate from the start. The student was then asked for the justification for this position and answered as follows:

Student: Because, like, I don't want to be involved in him playing hooky, because if I tell the teacher that he, well, I just can't, if I promise him, and then I tell the teacher, it will just be worse for me.

Now, one plausible interpretation of this is that the student argued from egoistic motives, despite previously stating that one should not act egoistically. This seems intrapersonally complex as it indicates a divergence between decision methods and criterion of rightness. That is, the student considered it morally correct to have one kind of rightness criterion an egoistic principle determining the moral status of the action in question - and another kind of decision method - behaving kindly, which, according to the student, included behaving non-egoistically.

One interpretation is that the student considered it morally acceptable to have egoistic motives, as long as these motives do not show in interaction with other students, for instance during a soccer game. However, this might not be a completely satisfactory interpretation, since the hypothetical student in the dilemma would be interacting with a classmate and, as a result, out of egoistic motives, would not act to fulfill the classmate's preference of making and keeping the promise. The egoistic motives could thus show in such a situation as a consequence of the hypothetical student's action, which was justified by the interviewed student. Hence, in comparing and reintegrating parts and the whole 
of the student's reasoning, one could consider this interpretation to suffer from some disadvantages. Another, and perhaps more promising interpretation, is that the student held it to be morally acceptable to act egoistically to some degree. This interpretation would then be warranted by the following parts of the student's first reply: 'Not being too egoistic, in other words only thinking of yourself.' And the second reply '.... it feels so strange to be with someone who is much too egoistic, like only thinking of himself' (italics by the authors). In that case, the rightness criterion and decision method were still - to some degree, though not fully - divergent.

\section{Discussion and concluding remarks}

In this study, we found six forms of inter- and intrapersonal variety in students' moral reasoning through employing the distinction between decision method and criterion of rightness. The use of this distinction enabled a nuanced understanding of varieties in students' moral reasoning, and may well be used in large-scale studies, for example, to explore the rate of occurrence of each respective form of variety. Future research could also examine the potential context dependence of the different forms of varieties. Are there differences in how each respective form of variety is affected by different kinds of changes in context, and to what degrees are they sensitive to these changes? Current research on context dependence does not suffice to answer such questions, since the distinction between these forms of reasoning has not been used.

As noted in the Introduction, studying students' moral reasoning is widely used as a method in a broad range of educational research. The more fine grained understanding of moral reasoning presented in this paper could be used to facilitate new findings in future research through employment of the six forms of varieties as analyzing categories. For example, moral reasoning has been shown to correlate to such factors as delinquent behavior (Beerthuizen, Brugman, and Basinger 2013; Palmer 2003) and democratic abilities (Nilsson et al. 2015), and a future research endeavor of importance would be to study whether certain forms of varieties correspond more strongly to such factors than others. Such findings could further guide educational policy and classroom practice.

Moreover, the existence of varieties in moral reasoning, e.g., interpersonal varieties, in a school where a moral fostering approach to ethics in school has been used, suggests that the approach has been unsuccessful. On the other hand, findings of other kinds of varieties, e.g., intrapersonal varieties in rightness criterion dimension, if found in a school setting where a philosophical ethics approach has been taken, suggests that this approach was unsuccessful. Hence, simply noting the existence of varieties is not sufficient to determine whether it is the moral fostering or the philosophical ethics aims that has not been fulfilled. But utilizing the six forms of varieties enables such an assessment, since certain forms of varieties is especially problematic given the specific aims of the ethics education of the school in question. (cf. Gardelli, forthcoming; Gardelli, Alerby, and Persson 2014).

Hence, the six forms of varieties in students' moral reasoning here distinguished between facilitate assessment and research in educational matters that has not been possible before.

Let us now return to the second research question and discuss how SCDT explanations, based on variations in context, manage to account for the varieties found in this study. 
The interpersonal varieties found in and between both dimensions of moral reasoning in this study might very well be explained by interpersonally different external contextual factors, such as gender, culture, ethnicity, or socio-economic background (Smetana 2006; Wainryb 1991), or by different informational assumptions (Wainryb 1991; Turiel et al. 1991). Indeed, variation in children's moral reasoning in connection to different actions has been noticed in previous research (Smetana 2006), and this might also influence the interpersonal varieties.

However, some results of the present study appear not to reasonably fit into the SCDT explanations portrayed above. Let us once again discuss the student who was interpreted to express both consequentialist and Kantian reasoning. First, let us consider the explanations based on interpersonal contextual factors such as differences in culture, ethnicity, socioeconomic background, or gender. None of these are reasonable explanations in this case, since it is a case of intrapersonal variety: it regards the same student, and hence no such varieties in context are present. ${ }^{6}$ (Indeed, it is possible that such factors are positively related to the existence of such variety.)

Second, explanations based on changes in informational assumptions do not suffice either, since the justification in terms of different rightness criteria (reasoning from both hypothetical and actual consequences) applies to the same hypothetical situation and decision method (being 'fair'), and there is no particular reason to believe that the student changed the informational assumptions during or in between the replies.

Third, the variety regarded the same hypothetical situation, and hence the same dilemma character, as well as the same action or character trait. Thus, explanations based on changes in these are not appropriate either.

Another possible explanation is the student's adaptation of rightness criteria to the student's beliefs about the interviewer's intended outcomes. However, this is not the most warranted interpretation, given our data. The student was straightforward and determined during the expression of the rightness criterion, and interrupted the interviewing author during the posing of questions rather than expressing insecurity regarding the student's positioning in the rightness criterion dimension of moral reasoning.

Hence, the discussed SCDT explanations do not suffice to explain the case of intrapersonal variety in moral reasoning in the criterion of rightness dimension found in this study, as cited above. If this is correct, new explanations need to be proposed. However, since the present study is exploratory research with just a small sample, further studies are required. This study does not opt for generalizable results, but establishes a hypothesis about the insufficiency of the discussed SCDT-explanations to account for each and every instance of moral variety.

There are several relevant kinds of explanations other than the portrayed SCDT explanations worth considering. It is possible that limiting cognitive factors such as low working memory wholly or partly account for the intrapersonal variety in rightness criterion dimension. However, while that explanation is indeed possible, it seems unlikely, since the cited replies are all given within a very short timeframe. Other remaining possible explanations are a low logical-linguistic ability of expressing moral thinking and its formal composition, and the possibility of the student's acceptance of logical inconsistencies within moral frameworks. None of these two explanations can be ruled out with certainty.

In conclusion, while previous research has distinguished between issues of, for example, interpersonal and intrapersonal varieties in moral reasoning, this study provides 
a framework for, and has found empirical evidence for the existence of, six forms of varieties in moral reasoning, based on the distinction between decision method and criterion of rightness in moral reasoning. Some of these are suggested as not fitting into standard models of explanation. While this is a small sample explorative research study, it would be beneficial to have larger-scale studies test the results. Moreover, these findings lead to at least two interesting future research endeavors, which cannot be explained using present data; first, an examination of the nature (and degree) of context dependence of each of these forms of varieties, and second, a revisiting of prior models of explanation of varieties in moral reasoning.

\section{Acknowledgements}

First of all, we would like to thank the students who participated in the study. We also thank the parents, principals, and teachers for making this study possible. Furthermore, we are grateful to anonymous reviewers for constructive and helpful comments on previous versions of this article.

\section{Funding}

The present study has been carried out thanks to support from two grants from the Swedish Research Council [grant number Dnr 2008-5334 and 721-2013-2161]. Both authors are employed at Luleå University of Technology, a public university (independent, national university) in Sweden. The research study was approved by the Regional Ethics Review Board (Dnr 45-2009 and 760-2010) in Sweden.

\section{Disclosure statement}

The authors declare that they have no conflict of interest.

\section{Notes}

1. Email: viktor.gardelli@ltu.se.

2. Kohlberg has indeed given arguments against this claim, for example clarifying that within the principle of justice, a kind of care perspective was included through a principle of benevolence to all people, which can be seen as a kind of care (cf. Kohlberg, Boyd, and Levine 1990).

3. It might be thought that the interpersonal variations to be presented below can be explained by the differences in ages, but interpersonal variations were found within the same age groups.

4. As we have said, one might have a decision method that is very closely related to ones criterion of rightness. Hence, for each case, we have, in our analysis, tried to interpret whether the student meant a certain statement as a decision method, a criterion of rightness, or both. The reader could also find Kohlberg's discussion of deontic judgments versus judgments of what is right to be of interest (Kohlberg 1984).

5. The student used the Swedish word 'schyst' ('sjyst'/'juste'), which is historically related to the English word 'justice,' and could translate to, for instance, 'fair,' 'kind,' 'just,' 'honorable,' 'decent,' 'correct,' and 'irreproachable.' It is used in such expressions as 'fair play.' Hence, we translated it into 'fair' in the rest of the text, in accordance with advice from a professional translator.

6. It could be argued that the interview itself is a context, and as the interview progresses, the context changes. We will make two short comments here. First, if such a view is adopted, could there be any two statements given in the same context, such that the contextual explanation could be rejected, or is it impossible to find evidence against it? Second, we have here presented and discussed statements that are seen as varying that were given very close in time to each other, in situations where it does not seem intuitive to believe that any (significant) change in context had taken place. 


\section{References}

Backman, Y., E. Alerby, U. Bergmark, Å. Gardelli, K. Hertting, C. Kostenius, and K. Öhrling. 2012. "Improving the School Environment from a Student Perspective." Education Inquiry 3 (1): 19-35. doi:10.3402/edui.v3i1.22011.

Bales, R. 1971. "Act-Utilitarianism: Account of Right-Making Characteristics or Decision-Making Procedure?" American Philosophical Quarterly 8: 257-265.

Bebeau, M. J. 2002. "The Defining Issues Test and the Four Component Model: Contributions to professional education." Journal of Moral Education 31 (3): 271-295. doi:10.1080/ 0305724022000008115.

Beerthuizen, M. G. C. J., D. Brugman, and K. S. Basinger. 2013. "Oppositional Defiance, Moral Reasoning and Moral Value Evaluation as Predictors of Self-Reported Juvenile delinquency." Journal of Moral Education 42 (4): 460-474. doi:10.1080/03057240.2013.803955.

Bentham, J. 2000 [1781]. An Introduction to the Principles of Morals and Legislation. Kitchener, Ont., Batoche.

Blackburn, S. 2008. Oxford Dictionary of Philosophy. Oxford: Oxford University Press.

Bosco, S. M., D. E. Melchar, L. L. Beauvais, and D. E. Desplaces. 2010. "Teaching Business Ethics: The Effectiveness of Common Pedagogical Practices in Developing Students' Moral Judgment Competence." Ethics and Education 5 (3): 263-280. doi:10.1080/17449642.2010.533049.

Bouchard, N., and R. W. Morris. 2012. "Ethics Education Seen Through the Lens of Habermas's Conception of Practical Reason: The Québec Education Program." Journal of Moral Education 41 (2): 171 -187. doi:10.1080/03057240.2012.668007.

Carpendale, J., and D. Krebs. 1992. "Situational Variation in Moral Judgment: In a Stage or On a Stage?." Journal of Youth and Adolescence 21 (2): 203-224. doi:10.1007/BF01537337.

Chaparro, M. P., H. Kim, A. Fernández, and T. Malti. 2013. "The Development of Children's Sympathy, Moral Emotion Attributions, and Moral Reasoning in Two Cultures." European Journal of Developmental Psychology 10 (4): 495-509. doi:10.1080/17405629.2012.742008.

Foot, P. 1972. "Morality as a System of Hypothetical Imperatives." Philosophical Review 81 (3): 305-316. doi: 10.2307/2184328.

Gardelli, V., E. Alerby, and A. Persson. 2014. "Why Philosophical Ethics in School: Implications for Education in Technology and in General." Ethics and Education 9 (1): 16-28. doi:10.1080/ 17449642.2014.890277.

Gardelli, V. forth. To Describe, Foster or Inquire: Reasoning, Ethics and Technology in School. Luleå: Luleå University of Technology.

Gilligan, C. 1982. In a Different Voice: Psychological Theory and Women's Development. Cambridge: Harvard University Press.

Gilligan, C., and G. Wiggins. 1988. "The Origins of Morality in Early Childhood Relationships." In Mapping the Moral Domain, edited by C. Gilligan, J. V. Ward, and J. McLean Taylor, 111-138. Cambridge: Harvard University Press.

Hurtado, S., M. J. Mayhew, and M. E. Engberg. 2012. "Diversity Courses and Students' Moral Reasoning: A Model of Predispositions and Change." Journal of Moral Education 41 (2): 201-224. doi:10.1080/03057240.2012.670931.

Johnson, R. 2004. "Kant's Moral Philosophy." In The Stanford Encyclopedia of Philosophy (Summer 2012 Edition), edited by E. N. Zalta. Retrieved from http://plato.stanford.edu/archives/ sum2012/entries/kant-moral/

Kant, I. 1988 [1785]. "Foundations of the Metaphysics of Morals." In Kant selections, edited by L. W. Beck, 244-298. New York: Macmillan.

Keefer, M. 2006. "A Critical Comparison of Classical and Domain Theory: Some Implications for Character Education." Journal of Moral Education 35 (3): 369-386. doi:10.1080/0305724 0600874547 .

Kohlberg, L. 1981. Essays on Moral Development. Vol. 1. The Philosophy of Moral Development: Moral Stages and the Idea of Justice. San Francisco: Harper \& Row.

Kohlberg, L. 1984. Essays on Moral Development. Vol. 2. The Psychology of Moral Development: The Nature and Validity of Moral Stages. San Francisco: Harper \& Row.

Kohlberg, L., D. Boyd, and C. Levine. 1990. "The Return of Stage 6: Its Principle and Moral Point of View." In The Moral Domain, edited by T. Wren, 151-181. Cambridge: The MIT Press. 
Mayhew, M., and P. King. 2008. "How Curricular Content and Pedagogical Strategies Affect Moral Reasoning Development in College Students." Journal of Moral Education 37 (1): 17-40. doi:10.1080/03057240701803668.

McLeod-Sordjan, R. 2014. "Evaluating Moral Reasoning in Nursing Education." Nursing Ethics 21 (4): 473-483. doi:10.1177/0969733013505309.

Ministry of Education and Cultural Affairs. 2003. The Act concerning the Ethical Review of Research Involving Humans, SFS 2003: 460.

Nilsson, D., V. Gardelli, Y. Backman, and T. Gardelli. 2015. "To Colorize a Worldview Painted in Black and White." International Journal of Humanities and Social Science 5 (1): 64-70.

Nucci, L., and E. Turiel. 1978. "Social Interactions and the Development of Social Concepts in Preschool Children.” Child Development 49 (2): 400-407. doi:10.2307/1128704.

Öhman, J., and L. Östman. 2007. "Continuity and Change in Moral Meaning-Making." Journal of Moral Education 36: 151-168.

Palmer, E. J. 2003. "An Overview of the Relationship Between Moral Reasoning and Offending." Australian Psychologist 38 (3): 165-174. doi:10.1080/00050060310001707177.

Passini, S. 2014. "The Effect of Personal Orientations Toward Intergroup Relations on Moral Reasoning." Journal of Moral Education 43 (1): 89-103. doi:10.1080/03057240.2014.884489.

Raaijmakers, Q., R. Engels, and A. Van Hoof. 2005. "Delinquency and Moral Reasoning in Adolescence and Young Adulthood." International Journal of Behavioral Development 29 (3): 247-258. doi:10.1177/01650250544000035.

Resnik, M. D. 1987. Choices: An Introduction to Decision Theory. Minneapolis: University of Minnesota Press.

Rique, J., and C. Camino. 1997. "Consistency and Inconsistency in Adolescents' Moral Reasoning." International Journal of Behavioral Development 21 (4): 813-836. doi:10.1080/016502597 384686.

Schmidt, C. D., C. R. McAdams, and V. Foster. 2009. "Promoting the Moral Reasoning of Undergraduate Business Students Through a Deliberate Psychological Education-Based Classroom Intervention." Journal of Moral Education 38 (3): 315-334. doi:10.1080/ 03057240903101556.

Senland, A. K., and A. Higgins-d'alessandro. 2013. "Moral Reasoning and Empathy in Adolescents With Autism Spectrum Disorder: Implications for Moral Education." Journal of Moral Education 42 (2): 209-223. doi:10.1080/03057240.2012.752721.

Sidgwick, H. 1907 [1874]. The Methods of Ethics (7th edition). London: Macmillan.

Smetana, J. G. 1999. “The Role of Parents in Moral Development." Journal of Moral Education 28 (3): 311-321. doi:10.1080/030572499103106.

Smetana, J. G. 2006. "Social-Cognitive Domain Theory." In Handbook of Moral Development, edited by M. Killen and J. Smetana, 119-153. Mahwah, N.J: Lawrence Erlbaum Associates.

Southwood, N. 2011. "The Moral/Conventional Distinction." Mind 120 (479): 761-802. doi:10. 1093/mind/fzr048.

Tännsjö, T. 1998. Hedonistic Utilitarianism. Edinburgh: Edinburgh University Press.

Turiel, E. 1983. The Development of Social Knowledge: Morality and Convention. Cambridge, UK: Cambridge University Press.

Turiel, E., C. Hildebrandt, C. Wainryb, H. D. Saltzstein, E. Turiel, C. Hildebrandt, and C. Wainryb. 1991. "Judging Social Issues: Difficulties, Inconsistencies, and Consistencies." Monographs of the Society for Research in Child Development 56 (2): i-119. doi:10.2307/1166056.

Wainryb, C. 1991. "Understanding Differences in Moral Judgments: The Role of Informational Assumptions." Child Development 62 (4): 840-851. doi:10.2307/1131181.

Wainryb, C. 2006. "Moral Development in Culture." In Handbook of Moral Development, edited by M. Killen and J. Smetana, 211-240. Mahwah, N.J: Lawrence Erlbaum Associates.

Zarinpoush, F., M. Cooper, and S. Moylan. 2000. "The Effects of Happiness and Sadness on Moral Reasoning.” Journal of Moral Education 29 (4): 397-412. doi:10.1080/713679391. 